\title{
BENCHMARKING THE CONSTRUCTION INDUSTRY: AN ADAPTATION OF THE WORLD MANAGEMENT SURVEY METHODOLOGY
}

\author{
Mauricio Bonilla ${ }^{1}$ and Tito Castillo ${ }^{2}$
}

\begin{abstract}
Benchmarking is a best management practice that allows companies to be compared and to improve. Some benchmarking studies in the construction industry have evaluated several dimensions with respect to management practices. Different methods have been used to benchmark the performance of construction companies. These methods are strenuous due to their extension and the variety of practices evaluated. Although there are benchmarking tools that have defined the minimum practices that should be evaluated in the management of industries from a lean approach, this has not yet been achieved for construction management.

Therefore, the objective of this research was to develop a benchmarking exercise of minimum management practices in construction, using a website to obtain information from construction companies through an adaptation of the World Management Survey (WMS) methodology. For this purpose, surveys were developed with a Lean approach and the content was validated by interviews with experts from the construction industry. Data was collected through a website that hosts the surveys. Results of this benchmarking study show that the majority of construction companies surveyed scored less than $50 \%$ in their management practices, which shows an opportunity for improvement for the companies evaluated.
\end{abstract}

\section{KEYWORDS}

Benchmarking, Management practices, Lean construction, Health and safety, Standardization.

\section{INTRODUCTION}

Benchmarking is considered a tool for self-assessment and comparison of companies that enables evaluation of the performance of a company compared to its competitors. It is also good management practice that drives improvement to reach world class standards (CDT 2002). The performance of a company depends largely on the management practices adopted by each organization (Cha and Kim 2018), because they are directly

Civil Engineer, Faculty of Engineering, National University of Chimborazo (UNACH), Av. Antonio José de Sucre Km 1 1/2 vía Guano Riobamba, Ecuador, mrbonilla.fic@unach.edu.ec, orcid.org/00000002-8049-8202

2 Professor, Civil Engineer, Faculty of Engineering, National University of Chimborazo (UNACH), Av. Antonio José de Sucre Km 1 1/2 vía Guano Riobamba, Ecuador, tcastillo@unach.edu.ec, orcid.org/0000-0002-3472-3456 
related to the profitability, productivity and survival rates of the company (Bloom and Van Reenen 2007). In the construction business, best management can make companies increase their productivity up to 32\% (Baladrón and Alarcón 2017).

There are different types of benchmarking; good practices seek to compare the tools that lead to better performance (Albertin et al. 2015; Pellicer et al. 2014; Ramírez et al. 2004).

Several benchmarking initiatives in the construction industry have been presented in many countries such as: United Kingdom (Egan 1998), United States (Construction Industry Institute (CII) 2000), Chile (CDT 2002; Opitz et al. 2016; Ramírez et al. 2004), Brazil (Costa 2003), Singapore and Hong Kong (Bakens et al. 2005), Colombia (Botero et al. 2007), and South Korea (Cha and Kim 2018), to mention a few. Those who have studied and developed performance measurement systems in both management and construction (Costa et al. 2006).

Likewise, numerous management practices have been defined. The Construction Industry Institute (CII) has proposed a framework that lists 11 best management practices, for companies and projects in the United States (Kim 2014). In Chile, Ramírez et al.(2004) present 15 management dimensions that were adapted by Opitz et al. (2016). Also in South Korea, Cha and Kim (2018) proposed a method of measuring project performance, focusing on 7 performance areas. Additionally, Bloom and Van Reenen (2007) defined 18 management practices in the manufacturing industry, arranging them into 4 groups of dimensions for their research.

Different methodologies have been developed to evaluate management practices. Bloom and Van Reenen (2007) conducted telephone interviews aimed at company managers, Ramírez et al. (2004) used surveys for work and office personnel, Opitz et al. (2016) used personal and telephone interviews, Cha and Kim (2018) collected project data through surveys and bibliographic compilations. In the aforementioned investigations, interviews and extensive surveys were applied because a large number of practices grouped in dimensions were evaluated. Several questions of the questionnaire were not answered by total or partial ignorance of each dimension, thus generating possible biases in the data obtained. However, it has not yet been defined how many dimensions and management practices are the minimum and necessary to evaluate the management of construction companies. Each researcher or practitioner recommends a different methodology and it is not clear which is the most appropriate to develop this type of benchmarking for construction, although a methodological proposal should ensure efficiency in terms of the number of dimensions, practices and reliability of an evaluation instrument (Barth et al. 2019).

Aiming to overcome this benchmarking gap, this research defined a minimum set of Lean management practices in construction, through an adaptation of the World Management Survey (WMS) methodology. Construction companies self-evaluated their management practices through a website that registered their scores. By using their scores, a benchmarking of construction companies was carried out, which yielded results at the national level and by company size .

Applying a standardized management benchmarking in the construction industry can help construction companies assess and compare their Lean management practices with the intention of proposing continuous improvement actions to reduce waste and improve value generation. 


\section{METHODOLOGY}

The methodology applied in this research sought to obtain a benchmarking tool for management practices with a lean approach. The process developed is shown in Figure 1.

\begin{tabular}{c|c|}
$\sum$ & Scope \\
\hline & Development of a questionnaire \\
\hline & Testing and validation of the questionnaire \\
\hline & Creation of a website \\
\hline & Sample Selection \\
\hline
\end{tabular}

Figure 1: Research methodology

\section{STEP 1: SCOPE}

In the construction industry, management is applied in several areas. This research was applied to the management of construction companies that are dedicated to the provision of construction services, where the manager is responsible for controlling and ensuring that all aspects of construction are executed according to the standards and technical specifications within a established budget and schedule (Toomey 2019).

The WMS methodology was adopted for the development of this study. The most important aspects of this methodology that have been detailed in the publication of Bloom and Van Reenen (2010) were adapted. An advantage of that methodology is that it applies validated questionnaires with Lean practices common to the industry in general and that were applied in this construction benchmarking.

\section{STEP 2: DEVELOPMENT OF THE QUESTIONAIRE}

This work is based on an adaptation of the WMS. After a review of the content of the practices evaluated by Bloom and Van Reenen (2007), the dimensions of Talent Management, Goals, Operations Management and Performance Monitoring were adapted for the construction industry.

The operations management dimension include lean management practices. These when applied in the construction industry achieve great benefits such as higher quality in construction, better productivity and profitability, reduction of costs and deadlines, better risk management, greater customer satisfaction, and waste reduction (McGraw Hill Construction 2013). The operations dimension covers areas from the planning and programming of activities, the supply chain, inventory management, production and quality of construction projects (Nahmias 2010).

The Performance Monitoring dimension is based on key performance indicators (KPI). In manufacturing, firms alerts managers about management and processes deficiencies (Bloom and Van Reenen 2007). The same criteria is applied in construction industry. 
However, in construction, clear and measurable goals must be established (Egan 1998) with the intention of achieving the objectives of short and medium term to achieve high efficiency and productivity target setting must be applied (Serpell 2002).

In addition, Talent Management takes care of the most important element of the company from a lean point of view, since the role of workers is vital for the survival of any organization. Applying good human resources management practices helps to improve the performance and productivity of construction companies (Ngwenya and Aigbavboa 2017).

Furthermore, three aditional dimensions were considered important in construction: Occupational Health and Safety, Leadership and Change Management, and Enterprise risk. The latter were defined based on an extensive literature search and the criteria of the Project Management Institute (2013), as they are their own and relevant in the construction industry. Best management in Occupational health and safety reduces occurrence of injuries and loss of lifes, also improves productivity and the work environment (Serpell 2002).

Leadership and change management in construction is key in a growing and highly competitive environment where changes are constant at all levels of the company, so many efforts and resources are allocated to try to manage changes properly (Hussain et al. 2018; Motilla 2016). This requires leadership that fosters a participatory environment to design new forms of organization that emphasize learning, flexibility and rapid response.

Finally, the enterprise risk dimension is included because because the construction industry is exposed to economic, technological, political and social risks (Abella Rubio 2006) that can directly affect the objectives of a construction company generating additional costs for customers and contractors (Serpell et al. 2017). Therefore it is necessary to manage this type of risk to control the occurrence of uncertain events (Alarcón et al. 2011).

For the last three dimensions, questionnaires and questions were developed through matrices, which have specific processes, objectives and activities developed in each particular area. Each question was developed considering the why, how and what is achieved in each activity analyzed, the answers have absolute scales such as those of Bloom and Van Reenen (2010) where each management practice can reach a score of 1 (worst practice) and 5 (best practice).

\section{STEP 3: TESTING AND VALIDATION OF THE QUESTIONNARIE}

Once the dimensions, practices, questions and scoring scale were defined, the instrument was validated using the criteria of experts from many construction companies, who made judgments and evaluations of the entire questionnaire.

Afterwards, the corresponding corrections and adjustments were made to add or remove elements to the questionnaire and finally the test run of the evaluation instrument was made with three construction companies, the same ones that were named as company $\mathrm{A}, \mathrm{B}$, and $\mathrm{C}$ due to confidentiality.This process served to realize that the instrument generated had quality, validity and reliability.

Once the surveys were processed and classified, the Cronbach Alpha test was used to measure the reliability of the type of internal consistency of the survey. For there to be a good consistency, the result of the coefficient must be at least 0.70 (Cronbach 1951). 


\section{STEP 4: CREATION OF A WEBSITE}

Because scheduling interviews demand several resources and many times it is not possible to obtain true answers from the interviewees, a website was created to openly apply surveys to companies interested in evaluating their management performance. A question was made for each management practice and the scoring scale was adjusted.

The website was designed using a PHP programming language through the Adobe Dreamweaver program, after a hosting and domain was hired to host the website, the survey database was created and saved through the program MySQL

The created site had a cover page, instructions for use, a section for builders to enter the name of the company and select the location and size of the company; these data were used for further analysis. The final questionnaires were also uploaded, the calculation of the score of each dimension was obtained through averages and equation 1 which was defined by Ramírez et al.(2004), the results on the website are presented in real time, using bar and radar charts.(Bloom and Van Reenen 2016; CDT 2002).

$$
\text { Dimension score } \left.=\frac{\sum \text { question score }}{5 * \text { number of question by dimension }} \quad \text { (Equation } 1\right)
$$

\section{STEP 5: SAMPLE SELECTION}

The sample size accepted for this research was based on the realization that construction companies are reluctant to share sensitive information, as this was the first study of its kind within Ecuador. Because of this, this research is exploratory and the findings are preliminary, justifying the use of non-probability sampling (Malhotra 2008).

In a non-probabilistic sampling for convenience, nearby construction companies willing to participate in this research were chosen. This type of sampling demands fewer resources compared to other methods, but there are limitations since the results cannot be generalized to a population and may present a bias in the selection of the respondent.

To reduce inaccurate and repetitive answers the research team controlled the survey hosted on a website so it could not be answered several times by the same person or company (Malhotra 2008). Construction companies were asked to enter the name, location and size of the company. In this way, it was checked that individuals from the same company does not repeat the surveys. In addition, this information served to classify each company by size according to the criteria established according to INEC (2017).

For confidentiality, the names of the companies that participated in this research are omitted; a code was assigned to each company and then classified according to its size.

\section{STEP 6: DATA COLLECTION}

The website link was disseminated through the Construction Chambers, that associates most of the construction companies and single constructors, who shared this tool among their partners. In addition, personal invitations were made to different construction companies in the country. Aiming to obtain the sample data for the analysis, the technical department of each Construction Chamber was requested to manage the responses by means of reminder messages to its partners on Sunday, Tuesday and Thursday and warning of the closing date of the website. A similar process was done with private construction companies by the research team. 


\section{RESULTS AND DISCUSSION}

Table 1 presents a final list of the 7 dimensions and the 34 lean management practices defined in this study by the literature review.

Table 1: Dimensions and management practices for the construction industry

\begin{tabular}{|c|c|c|}
\hline Dimension & Management practices & Refferences \\
\hline $\begin{array}{l}\text { Operations } \\
\text { management }\end{array}$ & $\begin{array}{c}\text { Introduction of modern techniques, } \\
\text { Reason for introducing modern } \\
\text { techniques, Standardization and Good use } \\
\text { of talent }\end{array}$ & $\begin{array}{c}\text { Bloom and Van Reenen } \\
\text { (2007); World Management } \\
\text { survey (2010) }\end{array}$ \\
\hline $\begin{array}{l}\text { Performance } \\
\text { Monitoring }\end{array}$ & $\begin{array}{l}\text { Process documentation and continuous } \\
\text { improvement, Performance monitoring, } \\
\text { Performance review, Performance } \\
\text { meetings and Consequence management. }\end{array}$ & $\begin{array}{c}\text { Bloom and Van Reenen } \\
\text { (2007); World Management } \\
\text { survey (2010) }\end{array}$ \\
\hline $\begin{array}{l}\text { Target } \\
\text { Settings }\end{array}$ & $\begin{array}{c}\text { Types and Balance of targets, } \\
\text { Interconnection of targets, Time horizon of } \\
\text { targets, target stretch, Clarity and } \\
\text { comparability of goals. }\end{array}$ & $\begin{array}{c}\text { Bloom and Van Reenen } \\
\text { (2007); World Management } \\
\text { survey (2010) }\end{array}$ \\
\hline $\begin{array}{c}\text { Talent } \\
\text { management }\end{array}$ & $\begin{array}{l}\text { Inculcate a mentality of talent, Build a } \\
\text { culture of high performance through } \\
\text { incentives and evaluations, Removal of } \\
\text { underperforming people making room for } \\
\text { talented people, Develop talent promoting } \\
\text { good performing staff }\end{array}$ & $\begin{array}{c}\text { Bloom and Van Reenen } \\
\text { (2007); World Management } \\
\text { survey (2010) }\end{array}$ \\
\hline $\begin{array}{l}\text { Occupational } \\
\text { Health and } \\
\text { Safety }\end{array}$ & $\begin{array}{c}\text { Work planning, } \\
\text { Guidance and training in SSO, Policies } \\
\text { and objectives, Organization, Planning, } \\
\text { Implementation, Evaluation and } \\
\text { improvement. }\end{array}$ & $\begin{array}{l}\text { Construction Industry Institute } \\
\text { (2003); Dekker (2011); ISO } \\
\text { (2018a); OHSAS (2007); } \\
\text { OSHA (2016) }\end{array}$ \\
\hline $\begin{array}{l}\text { Leadership } \\
\text { and Change } \\
\text { Management }\end{array}$ & Defrosting,Leadership,Change, Re freeze & $\begin{array}{l}\text { Bakari et al. (2017); Gallo } \\
\text { (2017); Greiman (2013); } \\
\text { Hussain et al. (2018); Lewin } \\
\text { (1947); Motilla (2016) }\end{array}$ \\
\hline Enterprise risk & $\begin{array}{l}\text { ID,Analysis and evaluation, Reply, } \\
\text { Implementation, Monitoring and control }\end{array}$ & $\begin{array}{l}\text { Alarcón et al. (2011); Castillo et } \\
\text { al. (2018); Choudhry and lqbal } \\
\text { (2013); ISO (2018b); } \\
\text { McGeorge and Zou (2013); } \\
\text { Project Management Institute } \\
\text { (2013); Serpell et al. (2017) }\end{array}$ \\
\hline
\end{tabular}

During the month that the website was kept open, a total of 58 surveys were obtained. They were subsequently analyzed and 17 surveys were eliminated because they did not appear to be legitimate (i.e. they did not show variability in their responses). In addition, these companies were not registered in the Superintendence of Companies (SUPERCIAS 2019), so it was considered undesirable activity, leaving 41 viable companies. These data 
were used to carry out the external benchmarking of Lean management practices implemented within each organization.

A response was obtained from 13 micro companies, 18 small, 8 medium and 2 two large companies.

The result of the Alpha de Cronbach coefficient was 0.91, which indicates that the internal consistency of the evaluation instrument is excellent (George and Mallery 2003). The high Alpha value may be due to the quality of the questionnaire, also because the construction companies that participated were really interested in measuring their management practices and because of the controls that were implemented in order to obtain reliable results.

The managemente practices scores were presented by histograms simulating Bloom and Van Reenen (2007). The scores of the 7 dimensions analyzed were calculated, obtaining a national average of 2.41, mode of 1.83 and median of 2.40 . The standard deviation was 0.53 and the error of the average 0.08 . The scores of the companies were transformed into standardized variables to know the number of standard errors that a score is found with respect to the average (Malhotra 2008).

In addition, the range and amplitude of the data were calculated to be able to distribute them in class intervals constituting a table of frequencies of the surveyed construction companies, these data were used to elaborate Figure 2.

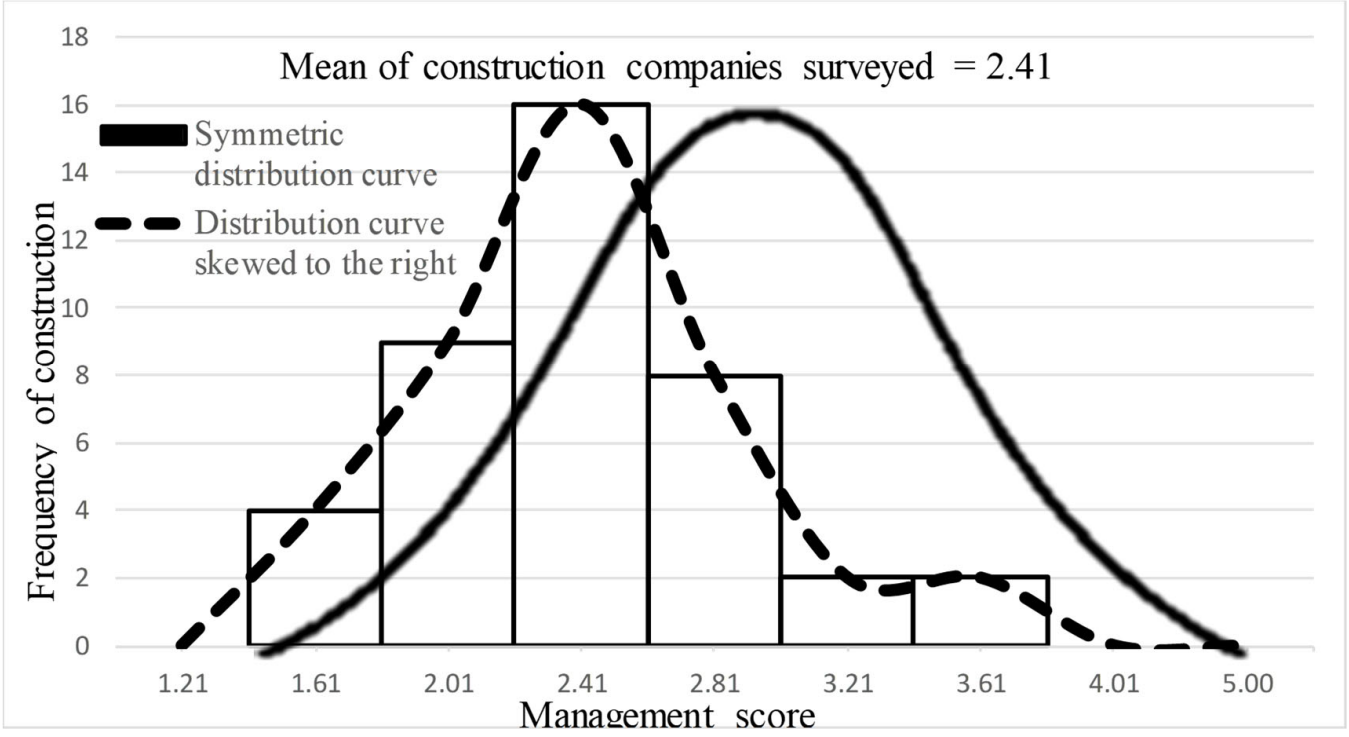

Figure 2: Distribution of scores of construction companies surveyed nationwide

In Figure 2 is depicted the curve of scores distribution of the companies surveyed. According to the position of the median, mode and average indicates a skewed curve to the right (Spiegel and Stephens 2009), this also was confirmed using Pearson's bias equations [S1 $=1.09 ; \mathrm{S} 2=0.06]$.

Most of the results are within the range of 1.81 to 2.60 and few companies have scores greater than 3. The average in the construction industry of Ecuador is close to a score of 2. According to Bloom, Kretschmer, and Van Reenen (2006), this means that the companies evaluated are poorly managed; the cause of these results may be due to a lack of external competition. 
The results are likely because in Ecuador according to the record of the superintendence of companies there are few foreign construction companies within the country (SUPERCIAS 2019). In case of an increase in external competition, inefficient companies would leave the market and only the most efficient ones would remain (Bloom and Van Reenen 2007).

Subsequently, the scores of the 41 construction companies were transformed to a percentage scale by means of equation 1 defined by Ramírez et al. (2004), where companies can reach a poor score $(0-0.25)$, bad $(0.25-0.50)$, good $(0.50-0.75)$ and excellent (0.75-1).

Finally, the benchmarking of the construction companies by size is presented (Figure 3 ), which was studied through the median of the management scores obtained by the size of each construction company.

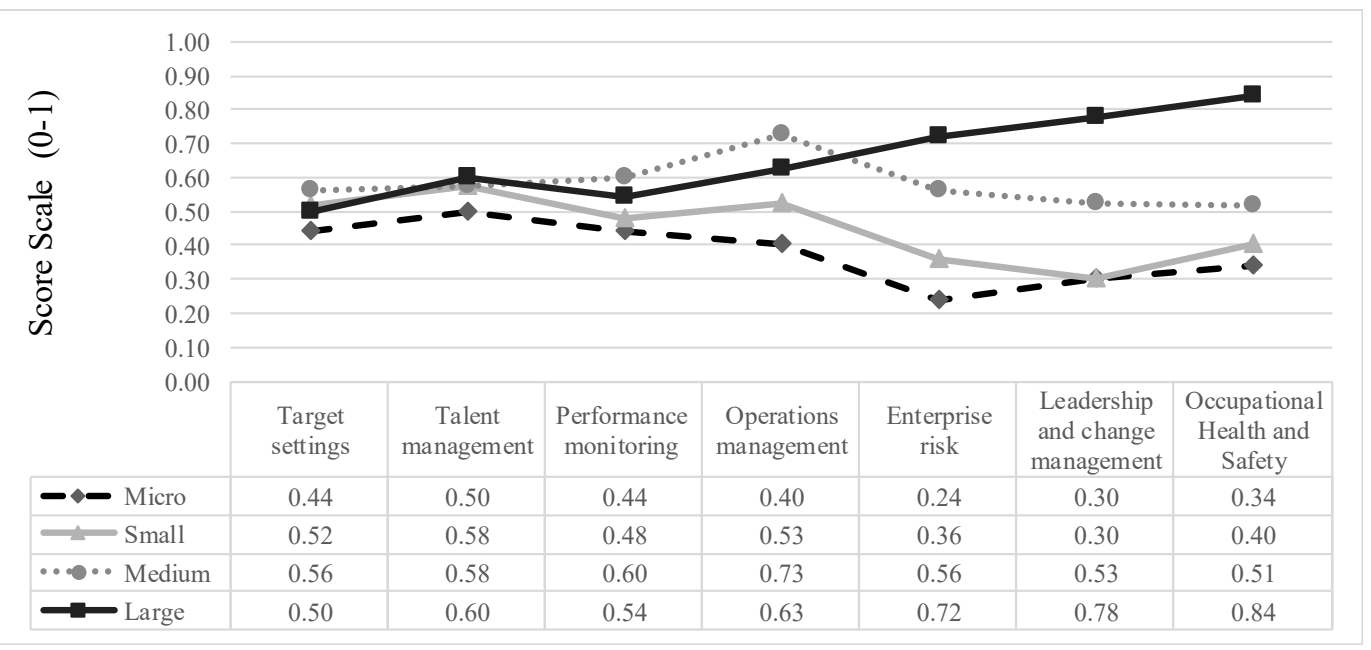

Figure 3: Benchmarking of the construction companies by size

Among the micro companies, six dimensions are below average, indicating poor management. On the other hand, small construction companies obtained dispersed scores ranging from bad management to good management. The medium-sized construction companies have stable scores since all dimensions are above average and suggest good management practices. Finally, the big construction companies get good and excellent scores.

The scores obtained by the companies according to their size could be related to the complexity of their organizations and the level of formality with which they carry out their management practices.

In Figure 3 we can see that talent management is maintained in a range between $50 \%$ and $60 \%$, the construction industry is labor intensive (El-Gohary and Aziz 2014),but management in this dimension does not exceed that range because of the high turnover of personnel (Campero and Alarcón 2014; Serpell 2002).

In addition, it can be noted that micro and small companies are not adequately managing the prevention of occupational accidents. This issue becomes important as the size of the construction company grows because, in addition to protecting its employees, occupational health and safety also helps to safeguard the assets of each organization. Also, there are legal regulations that becomes SSO a strategic management practice to achieve individual and business productivity (Paz et al. 2016). 
Furthermore, low business risk management can be observed in micro and small construction companies, as they have poor and bad scores respectively, because they tend to work without a risk management system (Oduoza et al. 2017). Medium and large companies obtained good and excellent scores because they have a risk plan to face adverse events that can affect the organizational objectives, costs and delays in the daily activities of a construction company (Hosny et al. 2018).

Regarding operations management, from micro to medium-sized companies there is a growth trend in this dimension, with a range of poor to excellent scores, these types of companies have begun to implement some Lean principles (Carvajal et al. 2019). In large companies seems to be a decrease vs medium companies, but there are only two data and it may not represent the reality of operations management in that size of construction company.

In addition, it can be seen that performance monitoring management grows simultaneously with the dimension of operations, because timely monitoring of construction activities can alert managers about specific problems within a project, this is done with the intention of improving the productivity of construction companies.

In the management of setting targets, it was observed that micro-sized to large-sized companies give similar importance to this dimension, since they have a development between $44 \%$ to $56 \%$, this may be due to the intermittency of the work carried out by the construction companies, which devote few resources and importance to this area.

However, it is noteworthy that the dimension of leadership and change management varies from less to more from micro-sized to large-sized companies and that this has no effect on Setting Targets (Gómez 2006; Parry 2011).

\section{CONCLUSIONS}

During this study, 7 dimensions and 34 management practices applied to the construction industry were defined. These were determined through a literature review and statistically validated with experts from different construction companies to be the minimum necessary to characterize construction management.

By adapting the World Management Survey (WMS) methodology, it was possible to create a tool to develop an external benchmark. A website collected information from 41 companies, which were able to evaluate their management practices. These data allowed to measure differences and diagnose management practices in different size construction companies.

The main contribution of this research is a questionaire to evaluate the minimum common management practices for construction companies, with a Lean aproach. The website containing the questionnaire is available for free through the link: http://www.benchmarkingempresasconstructoras.com/

The results show that a minimum set of management practices of construction companies can be defined and measured using the proposed methodology. This information can be used by the construction companies for benchmarking and improvement of management practices.

A limitation of this research is the size of the sample, especially given the few responses obtained from large construction companies. Also, the results from this study cannot be generalized because non-probabilistic sampling was used to collect the data. In addition, because only minimum dimensions were considered, it must be acknowledged that there was little flexibility to compare the companies that appeared in this study. 


\section{REFERENCES}

Abella Rubio, R. 2006. "COSO II And the integral management of business risks." Financial Strategy, 21(225), 20-24.

Alarcón, L. F., Ashley, D. B., De Hanily, A. S., Molenaar, K. R., and Ungo, R. 2011. "Risk planning and management for the panama canal expansion program." Journal of Construction Engineering and Management, 137(10), 762-771.

Albertin, M. R., Pontes, H. L. J., Frota, E. R., and Assunção, M. B. 2015. "Flexible benchmarking: a new reference model." Benchmarking: An International Journal, Emerald Group Publishing Limited, 22(5), 920-944.

Bakari, H., Hunjra, A. I., and Niazi, G. S. K. 2017. "How Does Authentic Leadership Influence Planned Organizational Change? The Role of Employees' Perceptions: Integration of Theory of Planned Behavior and Lewin's Three Step Model.” Journal of Change Management, Taylor and Francis, 17(2), 155-187.

Bakens, W., Viries, O., and Courtney, P. 2005. International review of benchmarking in construction. Research Rep. PSIBOUW, Amsterdam, The Netherlands.

Baladrón, C., and Alarcón, L. F. 2017. "Assessing the impact of lean methods in mining development projects." Proc. $25^{\text {th }}$ Annual Conference of the International Group for Lean Construction, Heraklion, Greece, II, 137-144.

Barth, K. B., Formoso, C. T., and Sterzi, M. P. 2019. "Performance measurement in lean production systems: An exploration on requirements and taxonomies." Proc. 27th Annual Conference of the International Group for Lean Construction, Dublin, Ireland, 629-641.

Bloom, N., Kretschmer, T. and Van Reenan, J., 2006. Work-life balance, management practices and productivity. In International differences in the business practices and productivity of firms (pp. 15-54). University of Chicago Press.

Reenen, J. (2007). "Measuring and explaining management practices across firms and Countries." The Quarterly J. Economics, CXXII(4), 1351-1408.

Bloom, N., and Van Reenen, J. (2010). "New Approaches to Surveying Organizations." American Economic Review, 100(2), 105-109.

Bloom, N., and Van Reenen, J. 2016. "Management as a Technology?".

Botero, L., Ramírez, C., and Álvarez, M. 2007. "Benchcolombia, Benchmarking System for Construction.” Engineering Magazine, 25, 33-45.

Campero, M., and Alarcón, L. F. 2014. Civil projects administration. (Catholic University of Chile, ed.), Santiago de Chile,Chile.

Carvajal, D., Bahamón, S., Aristizábal, P., Vásquez, A., and Botero, L. F. 2019. "Relationships between lean and sustainable construction: Positive impacts of lean practices over sustainability during construction phase." Journal of Cleaner Production, Elsevier Ltd, 234, 1322-1337.

Castillo, T., Alarcón, L. F., and Pellicer, E. 2018. "Finding Differences among Construction Companies' Management Practices and Their Relation to Project Performance." Journal of Management in Engineering, 34(3), 05018003.

CDT. 2002. National Benchmarking System for the construction sector. Chile.

Cha, H. S., and Kim, K. H. 2018. "Measuring Project Performance in Consideration of Optimal Best Management Practices for Building Construction in South Korea." KSCE J. of Civil Engineering, 22(5), 1614-1625.

Choudhry, R. M., and Iqbal, K. 2013. "Identification of Risk Management System in Construction Industry in Pakistan.” J. Management in Engineering, 29(1), 42-49. 
Construction Industry Institute. 2003. Safety plus: making zero accidents a reality. Research Summary 160-1, Austin, Texas,EE.UU.

Construction Industry Institute (CII). 2000. CII Benchmarking and Metrics. Research Summary 166, Austin, Texas,EE. UU.

Costa, D. 2003. "Guidelines for Design, Implementation, and Use of Performance Indicator Systems for Civil Construction Companies." Federal University of Rio Grande do Sul.

Costa, D. B., Formoso, C. T., Kagioglou, M., Alarcón, L. F., and Caldas, C. H. 2006. "Benchmarking Initiatives in the Construction Industry: Lessons Learned and Improvement Opportunities." J. Management in Engineering, 22(4), 158-167.

Cronbach, L. J. 1951. "Coefficient alpha and the internal structure of tests." Psychometrika, 16(3), 297-334.

Dekker, S. 2011. Drift into Failure. Ashgate Publishing Company, United Kingdom.

Egan, J. 1998. Rethinking Construction. London.

El-Gohary, K.M., and Aziz, R.F. 2014. "Factors influencing construction labor productivity in Egypt." Journal of Management in Engineering, 30(1), 1-9.

Gallo, G. 2017. "Importance of leadership for the implementation of management models in construction companies in Ecuador. Master's Degree in Planning and Management in Civil Engineering, Polytechnic university of Valencia.

George, D., and Mallery, P. 2003. SPSS for Windows step by step : a simple guide and reference, 11.0 update. (Allyn and Bacon, ed.).

Gómez, R. 2006. "Business leadership for technological innovation in micro, small and medium-sized companies." University and Company, 5(11), 62-91.

Greiman, V. 2013. Megaproject Management. John Wiley and Sons, New Jersey.

Hosny, H.E., Ibrahim, A.H., and Fraig, R.F. 2018. "Risk management framework for Continuous Flight Auger piles construction in Egypt." Alexandria Engineering Journal, Elsevier B.V., 57(4), 2667-2677.

Hussain, S. T., Lei, S., Akram, T., Haider, M., and Hussain, S. H. 2018. "Kurt Lewin's change model: A critical review of the role of leadership and employee involvement in organizational change." Journal of Innovation Management, 3(3), 123-127.

INEC. 2017. Directory of companies and establishments. Ecuador.

ISO. 2018a. ISO 45001 standard: Occupational health and safety management systems Requirements with guidance for their use. Switzerland, 1-64.

ISO. 2018b. ISO 31000 Standard: Risk Management. Guidelines. Switzerland, 1-26.

Kim, S. B. 2014. "Assessment of CII Best Practices usage in the construction industry." KSCE Journal of Civil Engineering, 18(5), 1228-1238.

Lewin, K. 1947. "Frontiers in group dynamics." Human Relation, 1(1), 5-41.

Malhotra, N. K. 2008. Market research. (P. Guerrero, ed.), Pearson Education, Inc., Naucalpan de Juárez, México.

McGeorge, D., Zou, P., and Palmer, A. 2013. Construction Management: New Directions. John Wiley and Sons, ed.), UK.

McGraw Hill Construction. 2013. Lean Construction: Leveraging Collaboration and Advanced Practices to Increase Project Efficiency SmartMarket Report. Bedford, MA: McGraw Hill Construction. Motilla, A. (2016). "Change management: application to the construction sector." Master's Degree in Planning and Management in Civil Engineering, Polytechnic university of Valencia.

Nahmias, S. 2010. Operations Management: Tricks to Manage Resources. (Bresca, ed.), Barcelona, Spain. 
Ngwenya, L., and Aigbavboa, C. 2017. "Improvement of productivity and employee performance through an efficient human resource management practices." Advances in Intelligent Systems and Computing, Springer Verlag, 727-737.

Oduoza, C. F., Odimabo, O., and Tamparapoulos, A. 2017. "Framework for Risk Management Software System for SMEs in the Engineering Construction Sector." Procedia Manufacturing, Elsevier B.V., 11, 1231-1238.

OHSAS. 2007. OHSAS 18001 Standard: Occupational Health and Safety Management System - Requirements. 1-35.

Opitz, C., Salvatierra, J. L., Castillo, T., and Alarcón, L. F. 2016. "Methodological proposal to assess management practices for incorporating benchmarking into the Chilean construction industry." VII Elagec, Bogotá, Colombia, 1-9.

OSHA. 2016. Recommended Practices for Safety and Health Programs in Construction. Washington D. C., EE.UU.

Parry, K. 2011. "Leadership and organization theory." The Sage handbook of leadership, A. Bryman, D. Collinson, K. Grint, B. Jackson, and M. Uhl-Bien, eds., SAGE Publications Ltd, London, 53-70.

Paz, A., Soler, M., and Muñiz, J. 2016. "Occupational health and safety strategy organizational productivity in shipbuilding." Forum Humanes, 4(2), 149-163.

Pellicer, E., Yepes, V., Teixeira, J., Moura, H., and Catalá, J. (2014). Construction Management. Wiley, UK

Project Management Institute. 2013. Project Management Fundamentals Guide (PMBOK Guide). Newtown Square, Pensilvania,EEUU.

Ramírez, R., Alarcón, L. F., and Knights, P. 2004. "Management evaluation system as a complement to the national Benchmarking system for Chilean construction companies." Construction Engineering, 19, 5-16.

Serpell, A. 2002. Construction operations management.Alfaomega, Brazil.

Serpell, A., Ferrada, X., and Rubio, N. L. 2017. "Fostering the effective usage of risk management in construction." J. Civil Engineering and Management, 23(7), 858-867.

Spiegel, M. R., and Stephens, L. J. 2009. Schaum Statistics. (McGRAWHILL/INTERAMERICANA EDITORES, ed.), Mexico.

SUPERCIAS. 2019. "Business ranking-Construction sector." Available at: https://appscvs.supercias.gob.ec/rankingCias/rankingCias.zul?id=F\&tipo=5.

Accessed: 13 June 2020

Toomey, C. 2019. Program Project and Construction Management Introduction. Available at: https://www.coursera.org/lecture/construction-projectmanagement/program-project-and-construction-management-introduction-CPB4x. Accessed: 13 June 2020

World Management survey. 2010. Summary of management questions in all sectors. Available at: https://worldmanagementsurvey.org/survey-data/methodology/. Accessed: 13 June 2020. 